A list of Working Papers on
the last pages

No. 174, 1986

THE INVESTMENT FUNDS SYSTEM

RECONSIDERED

by

Jan södersten

This is a preliminary paper. comments are welcome.

Dec., 1986

Revised Jan., 1988 


\section{THE INVESTMENT FUNDS SYSTEM RECONSIDERED}

over the past decades, governments of most industrialized countries have attempted to promote capital formation by enacting various schemes of investment incentives. A widely publicized scheme is the investment funds system (IF), set up as a component of the swedish corporation income tax.

The original idea behind the IF system was to induce firms to reserve profits during boom years and use them for investments during subsequent recessions. In its present form, the system began in 1955, but funds were not released until 1958. Since the end of the $1960^{\circ} \mathrm{s}$, funds have been released more and more frequently. In particular, efforts during the $1970^{\circ} \mathrm{s}$ to stimulate industrial growth meant that firms coula use the IE system almost continuously for new investments.

Investments "financed" through releases of investment funds receive a substantial subsidy, comparable to that obtained from the use of free depreciation. This led researchers to conclude that releases of investment funds will cause a sharp reduction in the cost of capital providing an inducement to invest ${ }^{1}$. In a recent article Bergström and södersten (1984) question this "conventional

1 see for example Praski (1978), Kanis (1979), Bergström (1982), and Taylor (1982). 
view" of the IF-system, and suggest that under certain quite plausible assumptions releases of investment funds may in fact have little impact on a firm's marginal incentive to invest. 1

The core of this "new view" argument is that each firm faces an upper limit on the use of the investment funds during a release period. This limit is set by the amount of money the firm has "allocated" to its own investment fund in past years, but not previously withdrawn for investments. When this limit is reached additional investment cannot be "financed" through the IF system and the firm, therefore, has to resort to the use of regular depreciation allowances.

The first purpose of this paper is to make the intuitive reasoning of Bérgström and södersten more precise and transparent by developing their argument within an explicit optimizing framework.

Allocations to investment funds take the form of deductions against taxable profits and the tax code restricts the annual allocation to a maximum of 50 per cent of taxable profits. A crucial (implicit) assumption of earlier studies is that the "representative firm" does allocate this maximum proportion of profits to its investment fund each year. Although such behavior would minimize tax payments, empirical evidence suggests that many Swedish firms

1 This "new view" of the IF-system was first developed by Södersten-Lindberg (1983). 
in fact do not pursue a policy of maximum IF-allocations.

The second main purpose of this paper, then, is to analyze the effects of the IF-system when the firm is constrained in its fund allocations, below the maximum amounts allowed by the tax law. The allocation constraint modeled here assumes that after tax profits reported on the books must not be reduced below the annual dividend paid by the firm.

The main conclusion of the paper is that the conventional (and official) view of the IF-system requires some rather special assumptions. During periods when the funds are released, the "representative" firm must be able to finance all of the current investment from its $I F$ and it must also expect that it will not exhaust its own fund at any time in the future. Only then will IF-releases be approximately equivalent to the use of free depreciation for marginal investments. This general conclusion does not critically depend on whether the firm makes maximum allocations to its IF or not.

When these strong assumptions are not fulfilled the incentive effect of a fund release is much reduced. The precise impact in this case will depend on whether or not the firm is able to allocate as much money to its IF as permitted by the tax rules. If maximum allocations are made, the profitability of the marginal investment will depend on the regular rules of tax depreciation, rather than on the IFsystem. If instead the firm is constrained in its 
fund allocations below the legal maximum, an additional investment project will not affect the total tax payments of the firm. The profitability of the marginal investment will therefore be completely independent of the parameters of the tax system.

The effects of the investment funds system on the incentive to invest may conveniently be analyzed in terms of its impact on the cost of capital. We consider a model in which there is no uncertainty and in which the firm"s planning is done under perfect foresight. Its objective is therefore to maximize the present discounted value of future cash flows. We ignore shareholder taxes, because they have little impact on the problems considered here.

The corporate tax system may be characterized in terms of five parameters, $\gamma,{ }^{T} s, h, f$ and $b .{ }^{\tau} s$ is the statutory tax rate and $\gamma$ is the declining balance rate of fiscal depreciation. A fraction h of the inputed interest on the replacement value of the capital stock may be deducted against taxable profits. Up to $f$ percent of profits net of fiscal depreciation is exempt from tax, provided that the firm "allocates" an equivalent amount to an investment fund (appearing as an entry on the balance sheet). To obtain this tax reduction, however, the firm must deposit a fraction $b$ of the fund allocation interest free at the central Bank (while the 
remainder, 1-b times the allocation, may be used for any purposel.

When the investment funds are released, firms are allowed to withdraw from the Central Bank deposits corresponding to the fraction $b$ of the cost of investments considered to be "financed" by the fund release. As an offset to this, however, firms lose the possibility to deduct fiscal depreciation. since investments "financed" through the If-system are considered to be fully written off for tax purposes.

Let the value of the firm be

$V=\int_{0}^{\infty} D e^{-r t} d t$

where $D$ denotes cash flow and $r$ is the firm's (constant) nominal after tax discount rate.To simplify notation, time indices are omitted here and in the following. The firm's objective is to maximize its value, subject to several constraints. The first are the equations describing the evolution of the firm's capital stock and accounting capital stock, respectively.

$\ddot{K}=I-\delta K$

$\dot{C}=P_{K} I-\gamma C-R$

where $P_{K} I$ is gross investment, and $\delta$ is the rate of economic depreciation. Regular fiscal depreciation, which is allowed at the declining balance rate $\gamma$. equals $\gamma \mathrm{c}$. The accounting capital stock is reduced 
both by fiscal depreciation and by the current "release" of investment funds, $R$.

The firm's cash flow identity is:
$D=P E(K, L)-w L-\tau_{S}\left(P E-w L-r h P_{K} K-\gamma C-B\right)-$ $\mathrm{P}_{\mathrm{K}} I-\mathrm{bB}+\mathrm{bR}$

The tax bill is the tax rate $\tau_{\mathrm{s}}$ times "operating profits", PE - wL, less imputed interest on the capital stock, fiscal depreciation and the "allocation" to the investment fund, B. In connection with the IF-allocation, the firm is required to deposit $\mathrm{bB}$ with the central Bank. Similarly, it receives bR from the central Bank, when the amount $R$ is "released" from its investment fund.

There are two constraints on the amount of money the firm may allocate to its IF: first, and as already stated, we assume that the tax code limits the annual allocation to $f$ percent of profits, net of the deduction for imputed interest and fiscal depreciation:

$B \leqq f \cdot\left[P E-W L-r h P_{K} K-\gamma C\right]$

The second constraint takes care of the legal requirement in sweden that dividends must be paid out of current or accumulated book profits. Since IF-allocations reduce not only after tax accounting profits, but also book profits (because of the close connection in sweden between tax accounting and book profits), this provision may effectively limit the size of the firm's IF-allocation. 
To model this constraint we interpret $D$ as dividends and to simplify, we assume that each year's dividend must be paid out of the same year's after tax book profits. We therefore require that:

$B \leqq P E-w L-r h P_{K} K-\gamma C-\frac{D}{1-\tau}$

where $D / 1^{-T} \mathrm{~s}$ is the amount of pre-tax book profits required to cover the current dividend.

We require, furthermore, the investment fund's balance to be non-negative at all times

$$
I F \geqq 0
$$

The change in the fund's balance is by definition

$$
I F=B-R
$$

There are, finally two constraints on withdrawals from the fund, stating that the firm cannot at any time withdraw funds in excess of its current investment, and that the amount withdrawn cannot be negative. Eormally this means that

$$
\begin{aligned}
& R \leqq P_{K} I \\
& R \geqq 0
\end{aligned}
$$

The firm chooses $I, L$ and $B$ to maximize $V$ (equation (1) subject to equations (2) to (10). The firm's problem may be rewritten as 
$\max V=\int_{0}^{\infty} e^{-r t}\left[D+\lambda_{1}(\dot{K}-I+\delta K)+\lambda_{2}\left(D-P F+W L+T_{s}[P E-\right.\right.$

$$
\begin{aligned}
& \left.\left.w L-r h P_{K} K-\gamma C-B\right]+P_{K} I+b B-b R\right)+ \\
& \lambda_{3}\left(\dot{C}-P_{K} I+\gamma C+R\right)+\eta_{1}\left(B-f \cdot\left[P R-w L-r h P_{K} K-\gamma C\right]+\right. \\
& \eta_{2}\left(B-\left[P E-w L-\gamma C-r h P_{K} K-\frac{D}{1-\tau} I\right)\right. \\
& \left.+\beta_{1} I F+\beta_{2}(I E-B+R)+\beta_{3}\left(R-P_{K} I\right)+\beta_{4} R\right] d t(11)
\end{aligned}
$$

where $\lambda_{1}, \lambda_{2}, \lambda_{3}, \eta_{1}, \eta_{2}, \beta_{1}, \beta_{2}, \beta_{3}$ and $\beta_{4}$ are the Lagrange multipliers associated with the constraints.

The first order necessary conditions for an optimal program are:

$$
\begin{aligned}
& D: \quad 1+\lambda_{2}+\frac{\eta_{2}}{1-\tau_{s}}=0 \\
& I:-\lambda_{1}+p_{K}\left(\lambda_{2}-\lambda_{3}-\beta_{3}\right)=0 \\
& K: \lambda_{1}(\delta+r)-P E_{K}^{R}\left(\lambda_{2}\left(1-\tau_{s}\right)+\eta_{1} f+\eta_{2}\right)+ \\
& +r h P_{K}\left(-\lambda_{2} \tau s+\eta_{1} f+\eta_{2}\right)-\lambda_{1}=0 \\
& \text { B: } \quad-\lambda_{2}\left(\mathrm{~T}^{-\mathrm{b})}+\eta_{1}+\eta_{2}-\beta_{2}=0\right. \\
& \eta_{1}\left(B-f \cdot\left(P F-w L-r h P_{K} K-\gamma C\right)\right)=0 \\
& \eta_{2}\left(B-\left(P E-w L-r h P_{K} K-\gamma C-\frac{D}{1-T s}\right)\right)=0 \\
& c: \lambda_{3}(\gamma+r)+\gamma\left(-\lambda_{2} s^{+\eta} \eta_{1} f+\eta \eta_{2}\right)-x_{3}=0 . \\
& R: \quad-\lambda_{2} b+\lambda_{3}+\beta_{2}+\beta_{3}+\beta_{4}=0 \\
& P_{3}\left(R-P_{K} I\right)=0 \\
& \mathrm{p}_{4} \mathrm{R}=0
\end{aligned}
$$


IE: $\quad \beta_{1}+r \beta_{2}-\dot{\beta}_{2}=0$

$$
\beta_{1} I E=0
$$

By interpreting these conditions we can determine the effects of the IF-system on the cost of capital.

\section{The IF-system and the cost of capital}

\section{a) standard of comparison}

In order to obtain a clear standard of comparison, we will start by deriving the cost of capital in the absence of the IF-system. We therefore set ali parameters of equations $(12)-(18)$ associated with the IF-system $(B, R$, $f$, the $\pi: s$ and $\beta: S$ ) equal to zero, and solve for $\mathrm{PF}_{\mathrm{K}}^{\prime} / \mathrm{P}_{\mathrm{K}}$. This is the gross rate of return before tax on real investment on the optimal path, i.e. the (gross) cost of capital:

$\frac{\mathrm{PE}_{\mathrm{K}}^{\prime}}{\mathrm{P}_{\mathrm{K}}}=\frac{\frac{-\lambda_{1}}{\mathrm{P}_{\mathrm{K}}}}{1-\tau_{\mathrm{S}}}\left(s+r-\frac{\dot{\lambda}_{1}}{\lambda_{1}}\right)-\frac{\mathrm{rh} \tau_{\mathrm{S}}}{1-\tau_{\mathrm{s}}}$

where

$\frac{-\lambda_{1}}{\mathrm{P}_{\mathrm{K}}}=1+\lambda_{3}$

and

$-\lambda_{3}=\int_{s=t}^{\infty} \gamma \tau s^{-(\gamma+r)(s-t)} d s$ 
$-\lambda_{3}$ is thus the present discounted value of tax reductions from regular depreciation allowances, taken at the declining balance rate $\gamma \cdot-\lambda_{1} / \mathrm{P}_{\mathrm{K}}$ is therefore the "net cost of investment", that is, the net cost to the firm of acquiring an asset of unit value. ${ }^{1}$ For $\tau_{\mathrm{S}}$ and $\gamma$ constant over time, (19) simplifies to:

$\frac{P E_{k}^{\prime}}{P_{K}}=\left(\frac{1-\frac{\tau}{\gamma+r}}{1-\tau}\right)(\delta+r-\pi)-\frac{r h T s}{1-\tau} s$

where $\Pi=\frac{\dot{\mathrm{P}}_{\mathrm{K}}}{\mathrm{P}_{\mathrm{K}}}$

Equation (20) differs from the standard expression for capital cost only by the last term, which explicitly captures the effect of interest deductability. 2

When the rate of fiscal depreciation, $\gamma$, is greater than the rate of economic depreciation, $\delta$, depreciation allowances are said to be accelerated. A special and important case of accelerated depreciation is where firms are allowed to deduct investment expenditures for tax purposes. This is often known as free depreciation or expensing. Note then that since tax accounting values are given here in exponential form, the mathematical equivalent of free depreciation is that the rate of fiscal depreciation, $\gamma$, is infinitely large. Capital cost with free depreciation is therefore given by

1 This term is used by, for instance, King and Fullerton (1984).

2 cf. King and Fullerton (1984), p XXX. 
$\frac{P E_{K}^{\prime}}{P_{K}}=\delta+r-\pi-\frac{r h{ }^{\top} s}{1-\tau}$

where $\pi=\dot{P}_{K} / P_{K}$.

The important thing to notice from equation (21) is that the profits tax now lowers the cost of capital. This is a well-known result, which is driven by the combination of interest deductibility and free depreciation. 1

According to the conventional view of the IF-system, fund releases are approximately equivalent to the use of free depreciation. This conventional view is usually explained in the following intuitive way: Because IF-allocations are free of tax, only the share $1-f$ of profits is taxed at the statutory tax rate $\tau^{s}$. The fund allocation, which amounts to the fraction $f$ of profits, is instead

1 See for example King (1975) and King and Fullerton (1984). K\&F show that where the tax system allows both full deductibility of interest and free depreciation, the nominal net cost of capital is equal to the interest rate multiplied by unity minus the corporate tax rate. Where interest is not deductible, as is usually the case with respect to the opportunity cost of equity funds, free depreciation makes capital cost invariant with respect to changes in the tax rate, i.e. equal to the interest rate. These results also come out of the present model.

No interest deductability means that $h=0$. The net (real) cost of capital is then $\mathrm{PE}_{K} / \mathrm{P}_{\mathrm{K}}-\delta=r-\pi$. Since free depreciation means that a fraction ${ }^{\mathrm{T}} \mathrm{s}$ of the investment is financed by deferred tax which may be interpreted as an interest free loan to the firm (cf. Södersten, 1982), interest deductability cannot reasonably be granted on more than the proportion $1^{-\tau} \mathrm{s}$ of the capital stock. Putting $h=1-\tau \mathrm{s}$ in equation $(21)$ then gives the well known result that $P F_{K}^{\prime} / P_{K}-\delta=r(1-\tau s)-\pi$. 
"taxed" at the rate b, which is the proportion which must be paid to the central Bank. The "effective" tax rate, which we denote by $\mathrm{T}^{*}$, is therefore a weighted average of the statutory tax rate $\tau_{s}$ and the "deposit rate" b:

$T^{*}=T_{S}(1-f)+b f$

When the funds are released by the government, firms withdraw from the central Bank the amount b, per crown of investment considered to be "financed" through the system. The "net cost of investment" is therefore $1-b$, and cost of capital will then be

$\frac{\mathrm{PE}_{\mathrm{K}}^{\prime}}{\mathrm{P}_{\mathrm{K}}}=\left(\frac{1-\mathrm{b}}{1-\mathrm{T}^{*}}\right)(8+\mathrm{r}-\pi)-\frac{r h \mathrm{~T}^{*}}{1-\mathrm{T}^{*}}$

Equation (22) differs from equation (21), which states the cost of capital in the case of free depreciation, only to the extent that the statutory tax rate $\tau_{s}$ is different from the deposit rate $b$.

\section{b) General Results}

We are now ready to analyze the effects of the IF-system. The general expression for the cost of capital with the IF-system is obtained from equation $(14)$ as

$\frac{P E_{K}^{\prime}}{P_{K}}=\frac{-\frac{\lambda_{1}}{P_{K}}\left(\delta+r-\frac{\lambda_{1}}{\lambda_{1}}\right)}{-\lambda_{2}-T^{*}}-\frac{r h T^{*}}{-\lambda_{2}-T^{*}}$

where 


$$
\begin{aligned}
& T^{*}=-\lambda_{2} \mathrm{~s}+\eta_{1} f+\eta_{2}, \\
& -\lambda_{2}=1+\frac{\eta_{2}}{1-\tau_{\mathrm{s}}} \quad \text { (from equation 12) }
\end{aligned}
$$

and

$$
-\frac{\lambda_{1}}{P_{K}}=-\lambda_{2}+\lambda_{3}+\lambda_{3} \text { (from equation } 13 \text { ). }
$$

As will be evident below, $T^{*}$ is the firm's "effective" tax rate, the value of which will depend on what particular assumptions we make about the workings of the fund system. The multipliers $-\eta_{1}$ and $-\eta_{2}$ express the marginal benefit to the firm from allocating money to its IF. When maximum allocations are made, $-\eta_{2}=0$ and $-\eta_{1}>0$, whereas $-\eta_{2}>$ 0 and $-\eta_{1}=0$ when "the dividend constraint" on fund allocations is binding. $\lambda_{2}$ has an economically interesting interpretation as the marginal value of dividends, showing the change in the firm's market value resulting from an extra crown of dividends. Conversely, $-\lambda_{2}$ is the marginal valuation of retained earnings, or marginal Tobin's $q \cdot \lambda_{2} \lambda_{2}$ takes the value of unity when the firm allocates as much of its profits to its IF as allowed by the tax code $\left(\eta_{2}=0\right)$, and less than unity when maximum allocations are not made $\left(\eta_{2}<0\right)$. We shall return to this interpretation of $-\lambda_{2}$ in section $3 \mathrm{~d}$ below.

As before $-\lambda_{1} / P_{k}$ is the net cost of investment. In this general case it depends also on $\lambda_{2}$ and on $\beta_{3}$, which is the net marginal gain to the firm from an IF-release. From equation (17) it is immediately clear that $\beta_{3}=0$ when $R<p_{K} I$, i.e. when the amount of money released from the fund is less than 
current investment. The net cost of investment therefore depends not only on whether or not the system is in a release stage but also on whether the amount of money actually released from the firm's IF during a release period is sufficient to "finance" its current investment. If $R<\mathbb{P}_{K} I$ the marginal investment must be written off according to the rules of regular fiscal depreciation, rather than through the IE-system.

It should be clear from these remarks that the effects of the IF-system on the cost of capital in general cannot be determined without precise assumptions on which regime the firm is in, at present and in the future. The purpose of the following sections is to distinguish between six regimes, each having a different implication for the cost of capital. The regimes are characterized by whether or not the firm is constrained in its IF-allocations, by whether or not the system is in a release stage and by whether the amount released from the fund during a release period is sufficient to "finance" its current investments. It should be pointed out, that the different regimes are defined for the purpose of clarity and economic interpretation and that the firm, obviously, may switch between the different regimes over time. The model used here is indeed sufficiently general to allow for such switches.

\section{c) The Case of Maximum IE-AIlocations}

We start the analysis by assuming that the firm now and in the future allocates as much of its pre-tax 
profits to its IF as allowed by the tax code. This means that $\eta_{2}(s)=0$ for all $s$ and (by equation (23a)) that $-\lambda_{2}(t)=1$. Irrespective of whether the funds are released or not, the expression for the cost of capital (equation 23 above) then simplifies to

$\frac{\mathrm{PE}_{\mathrm{K}}}{\mathrm{P}_{\mathrm{K}}}=\frac{\frac{\lambda_{1}}{\mathrm{P}_{\mathrm{K}}}\left(8+r-\frac{\lambda_{1}}{\lambda_{1}}\right)}{1-\mathrm{T}^{*}}-\frac{r h \mathrm{~T}^{*}}{1-\mathrm{T}^{*}}$

where

$T^{*}=T_{S}(1-f)+b f+\beta_{2} f$

which is a weighted average of the statutory tax rate and the central Bank deposit rate plus the multiplier $\beta_{2}$. This multiplier will be in the focus of the following analysis and from equation (11) we find that (written with a negative sign) it is the marginal gain from increasing the size of the investment fund. The investment fund allocation (which is $f$ per crown of pre-tax profits) is therefore "taxed" at the rate $b+\beta_{2}$, which is the central bank deposit rate less the gain from increasing the firm's IF. From equation (18) we have that

$-\beta_{2}(t) \int_{s=t}^{\infty} \beta_{1}(s) e^{-r(s-t)} d s$

where ${ }^{\beta}{ }_{1}(s)$ is the shadow price of the stock of funds at time $s$. The value of $\beta_{2}(t)$ therefore depends on the entire future development of the fund. $\beta_{1}(s)$ is zero when the fund's balance is positive, and $\beta_{2}(t)$ is therefore zero only in the special and 
extreme case where the firm expects that in the future it will never exhaust its fund. Further increases in the stock of funds are then of no value to the firm. It is also clear from equation (26) that the sooner and the more often the firm expects to exhaust its fund, the higher is $-\beta_{2}(t)$. The maximum value of $-\beta_{2}(t)$ cannot be determined without further assumptions, however, but we shall return to this question below.

The basic results of the analysis for the first three regimes are summarizewd in Tables 1 and 2 . Table 1 gives the net cost of investment, $-\lambda_{1} / P_{K}$. and Table 2 shows, for special cases, the resulting expressions for the cost of capital.

Table 1 The net cost of investment $\left(-\lambda_{1} / P_{K}\right)$ in the case of maximum IF-allocations

Regimes $1-3$

\begin{tabular}{|c|c|c|}
\hline No release & Fund & release \\
\hline of funds & $R=P_{K} I$ & $\mathrm{R}<\mathrm{P}_{\mathrm{K}} \mathrm{I}$ \\
\hline $\begin{array}{l}1+\lambda \\
\langle 1\rangle^{3}\end{array}$ & $\begin{array}{l}1-b-\beta 2 \\
(2)\end{array}$ & $\begin{array}{l}1+\lambda \\
(3)\end{array}$ \\
\hline
\end{tabular}

Note: ( ) states regime number. $-\lambda_{3}$ is the present discounted value of tax savings from regular tax depreciation (see equation 28 ), and $-\beta 2$ is the marginal gain from increasing the size of the IF. The general expression for the cost of capital in the case of maximum IF-allocations is given by (24) above. 
Table 2 The cost of capital for regimes $1-3$ in some special cases

\begin{tabular}{|c|c|c|c|c|c|}
\hline \multirow{2}{*}{$\begin{array}{l}\text { No release } \\
\text { of funds } \\
\left(-\mathrm{B}_{2}=0\right)\end{array}$} & & \multicolumn{4}{|c|}{ Fund release } \\
\hline & & $\begin{array}{l}R=P_{K} I \\
\left(-\beta_{2}=0\right\rangle\end{array}$ & & $\begin{array}{l}R<P_{K} I \\
\left(-\mathrm{F}_{2}-\max \right)\end{array}$ & \\
\hline$\left(\frac{1-T^{*} \frac{\gamma}{\gamma+\mu}}{1-T^{*}}\right)(\delta+r-\pi)$ & $-\frac{r h T^{*}}{1-T^{*}}$ & $\left(\frac{1-b}{1-T^{*}}\right)(\delta+r-\pi)$ & $-\frac{r h T^{*}}{1-T^{*}}$ & $\left(\frac{1-T^{*} \frac{\gamma}{\gamma+r}}{1-T^{*}}\right)(\delta+r-\pi)$ & $-\frac{r h T^{*}}{1-T^{*}}$ \\
\hline (1) & & (2) & & $(3)$ & \\
\hline
\end{tabular}

Note: $-\beta_{2}-\max$ is given by equation (31) for regime 3. $T^{*}=\tau_{\mathrm{s}}(1-\mathrm{f})+\mathrm{fb}$ for regimes 1 and 2 , and $\mathrm{T}^{*}=\tau(1-f)+f \mathrm{~T}^{*} \frac{\gamma}{\gamma+r}$ for regime 3 . The statutory tax rate $\tau_{s}$ and the rate of fiscal depreciation $\gamma$ are assumed to be unchanged over time. We then get that $\pi=\dot{\lambda}_{1} / \lambda_{1}=$ $\mathrm{P}_{\mathrm{K}} / \mathrm{P}_{\mathrm{K}}$, which is the rate of change for investment goods prices. 
Let regime 1 represent the case where the funds are not released for financing investments. $R=0$ means that $\beta_{3}=0$. The net cost of investment is therefore

$-\frac{\lambda_{1}}{\mathrm{P}_{\mathrm{k}}}=1+\lambda_{3}$

where as before $-\lambda_{3}$ is the present discounted value of tax reductions from regular depreciation allowances:

$-\lambda_{3}=\int_{s=t}^{\infty} T^{*} \gamma e^{-(\gamma+r)(s-t)} d s$

The effective tax rate $\mathrm{T}^{*}$ is as defined above by equation (25). For regime 1, therefore, the effect of the IF-system is to turn the corporate tax rate into a weighted average of the statutory tax rate $\tau_{s}$ and the sum of the deposit rate $b$ and $\mathrm{\beta}_{2}$, which is (the negative of) the marginal gain from adding to the IF.

For regimes 2 and 3 we assume that IF-system is currently in a release stage, i.e., $R>0$. Regime 2 is where the amount of release is sufficient to "finance" current investment $\left(R=P_{K} I\right)$. This means that $-\beta_{3}(t)>0$ and from equations (17) and (13) we get the net cost of investment

$-\frac{\lambda_{1}}{\mathrm{P}_{K}}=1-\mathrm{b}-\mathrm{\beta}_{2}$ 
In this case, therefore, both the net cost of investment and the effective tax rate $T^{*}$ depend on $\beta_{2}$. The conventional view of the effects of IFreleases explained above (see equation (22)) turns out to represent an extreme case of this regime, namely where $\beta_{2}=0$, that is, it implicitly assumes that the firm will never exhaust its IF.

Regime 3 is the case where $R<P_{K} I$. This means that $\beta_{3}=0$, making

$-\frac{\lambda_{1}}{P_{K}}=1+\lambda_{3}$

where $\lambda_{3}$ is defined as in equation (28). The difference between the cost of capital under regime 1 , where the funds are not released, and regime 3 , where the funds are released but insufficient to "finance" all investment is therefore determined by the values of $\rho_{2}(t)$. Somewhat loosely we may conclude that if the firm proceeds over time from regime 1 to regime $3,-\beta_{2}(t)$ will be higher under regime 3 and the cost of capital therefore lower -though the difference need not be great. The reason for this may be seen from equation (26): As long as the firm is not allowed to use its IF, but keeps building it up, $\beta_{1}$ is zero.

It is also interesting to note that while the minimum value of $-\beta_{2}$ is zero under regime 1 , it must exceed zero for regime 3, since the assumption that $\mathrm{R}<\mathrm{P}_{\mathrm{K}} I$ implies that the firm is currently exhausting its fund. The maximum value of $-\beta_{2}$, on the other hand, is greater for regime 3 : It occurs in the 
extreme case where the firm expects a permanent release of funds and when it always will exhaust its fund. After a few manipulations, equations (16) and (17) give this maximum value as

$-\rho_{2}=b-\frac{\tau}{\gamma(1-f)}$

The effective tax rate $T^{*}$, defined by equation (25), then turns into

$$
\begin{aligned}
T^{*} & =\tau_{s}(1-f)+f \frac{\tau_{s} \gamma(1-f)}{\gamma(1-f)+r} \\
& =T_{S}(1-f)+f T^{*} \frac{\gamma}{\gamma+r}
\end{aligned}
$$

This expression for the effective tax rate has a clear economic interpretation: A fraction $1-f$ of profits will be taxed at the statutory tax rate "s" while the fraction $f$ is allocated to the IF. BY the assumption of a permanent release of funds, this extra fund allocation can immediately be used for (intramarginal) investment. The Central Bank deposit rate $b$ is therefore of no importance. There is, however, an implicit cost to the firm of the allocation, and this cost equals the increased tax payments due to the loss of regular depreciation allowances on the subsequent assets, financed by the allocation, i.e., $T^{*} \gamma /(\gamma+r)$. For this special case of regime 3 where the firm always exhausts its fund and expects the period of fund release to be extended indefinitely, the effect of the IF-system is therefore to turn the tax rate into a weighted average of the statutory tax rate and the implicit cost of fund allocation. This is the "new view" interpretation of the IF-system, developed in Bergström-Södersten (1984). 
We now proceed to the case where the firm now and in future allocates less money to its IF than allowed by the rules. We have allowed for this possibility by introducing a dividend constraint (equation (6) above) which is assumed to be binding in the following. This means that $\eta_{1}(\mathrm{~s})=0$ for all $\mathrm{s}$, and from equation (12), (15) and (23a) we get that

$T^{*}=\left(\frac{1-\tau}{1-b}\right)\left(b+\frac{\beta}{1-\tau^{\prime}}\right)$

Since in this case $\eta_{2}<0,-\lambda_{2}$, which is the stock market's marginal valuation of retained earnings (or new investment), is now less than unity. The reason for this is that profits now are "trapped" within the firm in the sense that any increase in dividends will tighten the dividend constraint on IE-allocations and force the firm to pay more in corporate tax. Put differently, shareholders would be willing to accept less than a crown"s worth of capital gains, for the marginal crown of retained earnings. We note here that this is the same undervaluation result as that obtained from the so called "new view" of equity finance. The point of this new view is that because personal taxes on dividends cannot be avoided and because capital gains receive a preferential tax treatment, the stock market will value new investments financed by retained earnings at less than their reproduction costs. 1

1 See Södersten-Bergström (1981), Bradford (1981) and Auerbach (1979). 
Equations (12) and (15) gives that

$-\lambda_{2}=\left(\frac{1-\tau}{s}\right)\left(1+\frac{\beta}{1-\mathrm{b}}\right)$

By equations (33) and $(34), \lambda_{2}-T^{*}=1-T_{S^{*}}$ The general expression for the cost of capital (equation (23) above) then simplifies to

$\frac{\mathrm{PF}_{\mathrm{K}}^{\mathrm{K}}}{\mathrm{P}_{\mathrm{K}}}=\frac{\frac{-\lambda}{\mathrm{P}_{\mathrm{K}}}\left(s+r-\frac{\lambda_{1}}{\lambda_{1}}\right)}{1-\tau_{\mathrm{S}}}-\frac{r \mathrm{rT}^{*}}{1-\tau_{\mathrm{S}}}$

where $T^{*}$ is the effective tax rate as given in (33) and $-\lambda_{1} / P_{K}$ is the net cost of investment.

We proceed as before by distinguishing between three regines, characterized by whether or not the IF-system is in a release stage and by whether or not the firm during a release period is able to finance its current investment through the IF. Table 3 sumarizes the implications for the net cost of investment in each of these three regimes (regimes number 4-6) and Table 4 gives the resulting expressions for the cost of capital for some special cases. 
Table 3 The net cost of investment $\left(-\lambda_{1} / \mathrm{P}_{K}\right)$ in the case of constrained IF-allocations. Regines 4-6

\begin{tabular}{|c|c|c|}
\hline No release & Eur & lease \\
\hline of funds & $\mathrm{R}=\mathrm{p}_{\mathrm{K}} \mathrm{I}$ & $\mathrm{R}<\mathrm{P}_{\mathrm{K}} \mathrm{I}$ \\
\hline$\left(\frac{1-\tau}{1-b}\right)\left(1+\frac{\beta_{2}}{1-\tau_{s}}\right)+\lambda_{3}$ & $\begin{array}{c}1-T^{\top} \mathrm{s} \\
(5)^{2}\end{array}$ & $\begin{array}{c}1-\tau_{\mathrm{S}} \\
(6)^{\prime}\end{array}$ \\
\hline
\end{tabular}

Note: ( ) states regime number. $-\lambda_{3}$ is the present discounted value of tax savings from regular tax depreciation (see equation (28)), and $-\beta_{2}$ is the marginal gain from increasing the size of the IF. The general expression for the cost of capital in the case of maximum IF-allocations is given by (35) above. 
Table 4 The net cost of capital for regimes 4-6 in some special cases

\begin{tabular}{lcc}
\hline $\begin{array}{l}\text { No release } \\
\text { of funds }\end{array}$ & $R=p_{K} I$ & Fund release \\
$\left(-\beta_{2}=0\right)$ & $(-\beta 2=0)$ & $R<p_{K} I$ \\
$\left(-\beta 2=b\left(1-\tau_{s}\right)\right.$ & \\
$\left(\frac{1-\frac{b r}{\gamma+r}}{1-b}\right)(s+r-\pi)-\frac{b h r}{1-b}$ & $8+r-\pi-\frac{b h r}{1-b}$ & $8+r-\pi$ \\
$(4)$ & $(5)$ & $(6)$ \\
\hline
\end{tabular}

Note: ( ) states number of regime. Eor regimes (4) and (5) $-\beta_{2}=0$, which is the minimum value, while for regime 6 , $-\beta_{2}=b(1-\tau s)$ (see equation $\left.(37)\right)$. 
Regime 4 is where the fund system is not in a release stage. This means that $\beta_{3}=0$ and by equations (13) and (34)

$\frac{-\lambda 1}{\mathrm{P}_{\mathrm{K}}}=\left(\frac{1-\tau_{\mathrm{S}}}{1-\mathrm{b}}\left(1+\frac{\mathrm{B}_{2}}{1-\tau_{\mathrm{s}}}\right)+\lambda_{3}\right.$

where as before $-\lambda_{3}$ is the present discounted value of tax savings from regular depreciation allovances. The net cost of investment and the cost of capital will thus depend on the current and future values of $\beta_{2}$ which in turn depend on the expected future development of the firm's IF. For the special case, where $\beta_{2}=0$, i.e., where the firm expects that it will never exhaust its fund, the effect of the IF-system(see Table 4 , regime 4 ) is just to replace the statutory tax rate $\tau_{s}$ in the standard expression for capital cost without the IF-system (see equation (20) above) by the central Bank deposit rate b. A comparison between regimes 1 and 4 for the special case of $\beta_{2}=0$, makes it clear, furthermore that the constraint on fund allocations modelled here is equivalent to allowing the firm of regime 1 to allocate all of its profits from its marginal investment (i.e. $f=1$ ) to its IF.

For regime 5 we assume again that the IF system is currently in a release stage, and that $R=P_{K} I$. This means that $B_{4}=0$. The net cost of investment then turns out to be (from equations (13), (17) and (34)): 
$-\frac{\lambda_{1}}{P_{K}}=1-\tau_{S}$

From equations (35) and (36) it is clear then that capital cost is affected by the tax system only to the extent that the tax code allows for deduction of interest. The higher the firm values additions to its IF (i.e. the lower is $\beta_{2}$ i note that $\beta_{2}<0$ ) - which occurs the sooner and the more often it expects to exhaust its IF in the future - the lower is $T^{*}$ and therefore the value of interest deductions. The highest value of interest deductions is when $\mathrm{B}_{2}$ is zero. This is the "excess funds" case where the firm expects that it will never exhaust its IE. In this special case the cost of capital therefore differs from that of free depreciation only to the extent that $b$ differs from ${ }^{\top} \mathrm{s}^{\text {. }}$

Regime 6 is where $R<P_{K} I$. This means that $\beta_{3}=0$ and the net cost of investment is again $1-{ }^{-} s^{\circ}$. In this case we are able to solve for $\mathrm{F}_{2}$. By equations (17) and (34)

$-\beta_{2}=b\left(1-T_{s}\right)+\lambda_{3}(1-b)$

making $T^{*}=-\lambda_{3}$. Equation (16) then simplifies to

$\lambda_{3} x-\lambda_{3}=0$

One solution to this differential equation - and the only one with economic significance - is $\lambda_{3}=$ 0 . The implication of this is that $\mathrm{T}^{*}=0$ and $-\beta_{2}=$ $b\left(1-T_{s}\right)$. Interest deductability is of no value and the cost of capital then becomes 
$\frac{\mathrm{PE}_{\mathrm{K}}^{\mathrm{r}}}{\mathrm{P}_{\mathrm{K}}}=\delta+r-\pi$

Combining the assumptions that the fund release is not sufficient to finance (the marginal) investment and that fund allocations are constrained below maximum, therefore makes capital cost completely independent of the parameters of the tax system.

To see the intuition behind this result, note that $-\lambda_{2}$, which is marginal Tobin's $q$, now is $1-\tau \mathrm{s}$. This discount in the valuation of the stock market is just sufficient to offset the effects of the tax making the cost of capital completely tax invariant.

e

\section{Effects of New Rules}

So far, we have implicitly assumed that the required deposit with the Central Bank (b) is lower than the statutory tax rate $\left(T_{s}\right)$. Because of this, IF allocations provide an attractive alternative to paying profits tax even if the funds are never used again for investment. 1

By new rules in force since 1985, however, $b$ is higher than $T$. Firms that allocate profits to their investment funds therefore have to pay a "fee" (equal to the difference $b-T s$ ), in exchange

$1 \mathrm{~b}$ was 0.46 during $1963-79$ and 0.5 1980-84, while Ts ranged between 0.52 and 0.58 . Since 1985 , however, $b$ is 0.75 and $\tau_{s} 0.52$. This increase might be seen as an attempt by the government to force firms to pay fees to the new wage-earners funds, rather than avoiding the fees by large IF-allocations. 
for expected future benefits when the funds are released.

The multipliers $-\eta_{1}$ and $\eta_{2}$ may be interpreted as the marginal benefits from allocating profits to the IF. Since $-\eta_{1} \geqq 0$ and $-\eta_{2} \geq 0$, positive allocations require that (by equation 15 ) $-\beta 2 \geqq b-\tau_{s} \cdot$ By the new rules $\left(b>{ }_{s}\right.$ ) this condition requires that $-\beta_{2}$, which is the marginal gain from increasing the firm's IF, is positive and outweighs the "allocation fee" $b-\tau_{s}$. The conventional and official view of the IF-system, which implicitly assumes that $-\beta_{2}=0$, is therefore not compatible with the condition required for positive fund allocations under the new rules.

\section{Conclusions}

The general conclusion which emerges from this paper is that the effects of the investment funds system critically depend on which regime the firm is in when the funds are released by the government and which regime it expects to be in in the future. It has to look to the future because the profitability of increasing the capital stock today depends on the effective tax rates that will prevail in the future and these depend, inter alia, on the future development of its own IF. A further illustration to the results is given in Table 5, which gives some numerical examples based on the equations of Tables 2 and 4 . The difference between regime 2 in the special case where $\beta_{2}=0$ - which represents the conventional view of the system -and the "- $2^{-\max }$ case of regime 3 is particularly striking. 
Table 5 Numerical illustration of capital cost effects of the investment funds system in some special cases

\begin{tabular}{llll}
\hline & $\begin{array}{l}\text { No release } \\
\text { of funds } \\
\left(-\beta_{2}=0\right.\end{array}$ & $\begin{array}{c}\mathrm{R}=\mathrm{P}_{\mathrm{K}} \mathrm{I} \\
\left(-\beta_{2}=0\right)\end{array}$ & $\begin{array}{c}\mathrm{R}<\mathrm{P}_{\mathrm{K}} \mathrm{I} \\
\left(-\mathrm{\beta} 2^{\max }\right)\end{array}$ \\
$\begin{array}{l}\text { Allocation to } \\
\text { IF }\end{array}$ & 6.6 & 1.7 & 6.0 \\
\hline Maximum & $(1)$ & $(2)$ & $(3)$ \\
\hline Below maximum & 6.5 & 1.5 & 5.0 \\
& $(4)$ & $(5)$ & $(6)$ \\
\hline
\end{tabular}

The following assumptions are used: $\gamma=0.2,8=$ $0.1, r=0.10, \pi=0.05, \tau_{s}=0.52, b=0.5, h=$ 0.35 . The cost of capital without the IF-system is then $6.6 \%$. Free depreciation reduces capital cost to $1.2 \%$, whereas without the corporate tax capital cost is $5.0 \%$. See $p .12$ for an explanation of this.

Note that the numbers given here are for the net cost of capital, defined as

$\frac{P F_{\mathrm{K}}^{\mathrm{I}}}{\mathrm{P}_{\mathrm{K}}}-\delta$.

" $-p_{2}$ max" is given by equation (31) for regime 3 and by equation (37) for regime 6 . 
The appropriate policy conclusions to be drawn from these results hinges on which of the regimes we have studied that represents the best characterization of the position of Swedish firms. This is, of course, an empirical question which must be settled through careful study of individual firm data. In this context it is interesting to note the marked change in tax policy that took place in sweden in the mid 70s. From its start in 1955 to the mid $70 \mathrm{~s}$ the IF-system was used primarily as a countercyclical instrument with releases in recessions. The crisis of the Swedish economy which emerged in the mid 70s, however, led the government to embark upon a new IE-policy. This new policy means repeated renewals of IF-releases, which $i$ practice, enabled firms during a 10-year-period to use their investment funds continuously. During this period of "permanent" releases, less than an average of 20 per cent of the investments of the manufacturing industry were actually "financed" through the IFsystem. This observation makes it rather unlikely that the "representative" firm then was able to finance its marginal investments through the IFsystem and that it expected never to exhaust its investment fund. As explained, these are the critical implicit assumptions behind the conventional - and official - view of the IF-system. The IFreleases may in practice have raised the return on intramarginal investments more than it improved investment incentives.

Finally, a few reservations are in order. The policy conclusions that may be drawn from the results of this paper, are, of course, no more reliable than is the underlying model of firm behavior. In 
particular, we have focused interest on the cost of capital effects. There might, for example, still exist a "liquidity effect" of IF-releases. Considering the poor performance of the swedish stock market during the second half of the $70 \mathrm{~s}$ making new share issues expensive and the remaining restrictions on credit availability, such effects may have been important determinants of investment demand. 


\section{References}

Anerbach, A., 1979, Share Valuation and corporate Equity Policy. Journal of Public Economics

Bergström, V., 1982, Studies in Swedish Post-War

Industrial Investments. Uppsala 1982.

Bergström, $V$. - sodersten, J., 1981, Double

Taxation and Corporate Capital cost. IUI

Conference Reports, 1981:1, eds. Eliasson, G. -

Södersten, J.

Bergström, $V$. - södersten, J., 1984, "Do Tax

Allowances stimulate Investment?" Scandinavian

Joumal of Economics, Vol. 86 , No. 2.

Bradford, D., 1981, The Incidence and Allocation

Effects of a Tax on Corporate Distributions,

Journal of Public Economics, 15.

Kanis, A., 1979, Demand for Factors of Production.

An interrelated model of Swedish Mining and

Manufacturing Industry, stockholm.

King, M.A, 1975, "Taxation, Corporate Einancial

policy and the cost of Capital - A comment."

Journal of Public Economics, No 4.

King, M.A, - Eullerton, D. (eds.), 1984, The

Taxation of Income from Capital: A comparative

study of the united states, united kingdom,

Sweden and West Germany. University of Chicago Press.

Praski, S., 1978, Econometric Investment Functions and an Attempt to Evaluate the Investment Policy in Sweden 1960-73. Uppsala.

Södersten, J., 1977, Approaches to the Theory of Capital cost: An Extension. Scandinavian Journal of Economics. No. 4. 
Sodersten, J., 1982, Accelerated Depreciation and the cost of Capital. Scandinavian Journal of Economics. No. 1 .

Södersten, J. - Lindberg, Th., 1983, "skatt pă bolagskapital." Eorskningsrapport nr 20. IUI, stockholm.

Taylor, J., 1982, The Swedish Investment Funds System as a stabilization policy Rule. Brookings Papers on Economic Activity. 